\title{
Predictors of mortality in patients with hereditary hemorrhagic telangiectasia
}

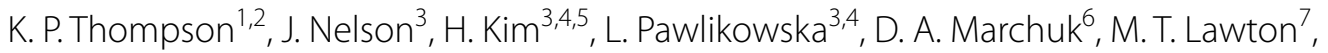 \\ Marie E. Faughnan ${ }^{1,2^{*}}$ (D) and the Brain Vascular Malformation Consortium HHT Investigator Group
}

\begin{abstract}
Background: Retrospective questionnaire and healthcare administrative data suggest reduced life expectancy in untreated hereditary hemorrhagic telangiectasia $(\mathrm{HHT})$. Prospective data suggests similar mortality, to the general population, in Denmark's centre-treated HHT patients. However, clinical phenotypes vary widely in HHT, likely affecting mortality. We aimed to measure predictors of mortality among centre-treated HHT patients. HHT patients were recruited at 14 HHT centres of the Brain Vascular Malformation Consortium (BVMC) since 2010 and followed annually. Vital status, organ vascular malformations (VMs) and clinical symptoms data were collected at baseline and during follow-up $(\mathrm{N}=1286)$. We tested whether organ VMs, HHT symptoms and HHT genes were associated with increased mortality using Cox regression analysis, adjusting for patient age, sex, and smoking status.

Results: 59 deaths occurred over average follow-up time of 3.4 years (max 8.6 years). A history of anemia was associated with increased mortality ( $H R=2.93,95 \% \mathrm{Cl} 1.37-6.26, p=0.006)$, as were gastro-intestinal (Gl) bleeding $(\mathrm{HR}=2.63,95 \% \mathrm{Cl} 1.46-4.74, p=0.001)$, and symptomatic liver VMs $(\mathrm{HR}=2.10,95 \% \mathrm{Cl} 1.15-3.84, p=0.015)$. Brain VMs and pulmonary arteriovenous malformations (AVMs) were not associated with mortality $(p>0.05)$. Patients with SMAD4 mutation had significantly higher mortality ( $H R=18.36,95 \% \mathrm{Cl} 5.60-60.20, p<0.001)$ compared to patients with ACVRL1 or ENG mutation, but this estimate is imprecise given the rarity of SMAD4 patients ( $n=33,4$ deaths).
\end{abstract}

Conclusions: Chronic Gl bleeding, anemia and symptomatic liver VMs are associated with increased mortality in HHT patients, independent of age, and in keeping with the limited treatment options for these aspects of HHT. Conversely, mortality does not appear to be associated with pulmonary AVMs or brain VMs, for which patients are routinely screened and treated preventatively at HHT Centres. This demonstrates the need for development of new therapies to treat chronic anemia, Gl bleeding, and symptomatic liver VMs in order to reduce mortality among HHT patients.

Keywords: Hereditary hemorrhagic telangiectasia, Vascular malformation, Arteriovenous malformation, Telangiectasia, Predictors of mortality

\section{Background}

Hereditary hemorrhagic telangiectasia (HHT) is a rare dominant genetic disorder with an estimated prevalence of approximately 1 in 5000-10,000 [1-5],

\footnotetext{
*Correspondence: Marie.Faughnan@unityhealth.to

1 Toronto HHT Centre, Li Ka Shing Knowledge Institute, St. Michael's Hospital, 30 Bond St, Toronto, ON M5B-1W8, USA

Full list of author information is available at the end of the article The Brain Vascular Malformation Consortium HHT Investigator Group authors are listed in acknowledgments.
}

affecting children and adults, often involving multiple organs. HHT is characterized by the presence of vascular malformations (VMs), including arteriovenous malformations (AVMs) of the lung, liver, brain, spinal cord and smaller mucosal lesions (telangiectasia) of the nose, mouth and gastro-intestinal (GI) tract $[6,7]$. These lesions lead to acute life-threatening bleeding, stroke, heart failure and death, as well as chronic bleeding from the nose and GI tract [8-12]. In other words, most HHT patients suffer from daily symptoms and are 
at risk of life-threatening complications. To date, there are no highly effective therapies to manage the chronic symptoms and only limited preventative management of serious complications. As novel therapies for HHT now become available, we need a paradigm shift in HHT research to be able to test these therapies and bring them to the patients that need them most. There is an urgent need therefore to understand mortality and other severe outcomes in HHT and their predictors.

Mortality and its predictors remain poorly understood in HHT to date. Retrospective questionnairebased studies [13-15] reported reduced median life expectancy of affected parents of HHT patients, with untreated disease, compared to non-HHT parents [13, 14] and to a general population in Germany [15]. These studies primarily reflect the care of HHT patients prior to HHT-centre based care, which has largely evolved over the last 20 years and has become more standardized since the publication of International HHT Guidelines [6]. One group [13] reported no difference in life-expectancy by HHT gene mutated, the other [14] reporting worse life-expectancy in patients with ENG mutation, with the largest difference in women. We speculate that this difference was related to complications of untreated lung AVMs and brain VMs, common in ENG mutation carriers, before the HHT centrebased care era of screening and treatment.

Administrative data also suggests reduced survival in HHT patients, compared to controls, in the UK [11], with a hazard ratio for death of 2.0 (CI 1.6-2.6) in HHT cases compared to controls, and a median age at death 3 years younger. However, this was based on historical data (1986-2011) from primary care practice, and therefore again likely that these results primarily reflect the routine care of HHT patients rather than specialized centre-based care, and also mostly prior to dissemination of the 2009 International HHT Guidelines [6]. In other words, likely few patients received preventative management for lung and brain AVMs.

The only prospective survival study is small, with 75 Danish patients followed for 20 years at one center and showed similar survival to controls [16], suggesting that patients treated at Specialized HHT Centres with routine preventative management may have better outcomes. Recent reports using US Nationwide Inpatient Sample (NIS) administrative data from 2000 to $2012[17,18]$ support this point, as patients with HHT hospitalized at high-volume centers $(>8 \mathrm{HHT}$ patients discharged per year) had better outcomes, with significantly lower in-hospital mortality $(1.2 \%$ vs $2.4 \%$; $p<0.001)$ and higher home discharge rates $(78.1 \%$ vs $71.6 \% ; p<0.001)$, compared to low-volume centres.
Few studies reported to date have detailed cause of death and none have identified predictors of mortality. This is particularly relevant in a multi-system disease such as HHT, where clinical heterogeneity is the rule, with widely variable clinical phenotypes. We aimed to measure predictors of mortality among centre-treated HHT patients.

\section{Methods}

Cohort The study includes 1286 HHT patients enrolled by the Brain Vascular Malformation Consortium (BVMC) at multiple recruiting centers in the US, Canada and the Netherlands between 2010 and 2018 with at least one follow-up visit or verification of death. Cohort recruitment has been previously described [12, 19]. All patients provided written informed consent. The study protocol was approved by the institutional review board at each recruiting centre. Patients were screened for organ VMs and other clinical features according to standard clinical practice and International HHT Guidelines [6], including: comprehensive history, physical, routine blood tests, screening for pulmonary AVM by contrast echocardiography, brain VM screening by magnetic resonance imaging, clinical screening for liver VM (chronic right upper quadrant pain, portal hypertension, high-output heart failure, liver bruit on examination, abnormal liver function tests) and clinical screening for recurrent spontaneous epistaxis ( $>1$ episode per month for $>1$ year), and HHT-related GI-bleeding (anemia, iron deficiency, known GI telangiectases on endoscopy, melena, rectal bleeding). As part of their routine clinical care, if screening was positive for pulmonary AVM or brain $\mathrm{VM}$, patients underwent further diagnostic imaging and treatment, where appropriate. If clinical assessment was suggestive of symptomatic liver VM, diagnostic imaging was recommended and therapy where appropriate. If initial clinical assessment was suggestive of HHT-related GI bleeding, then diagnostic endoscopy was recommended, and endoscopic, medical and supportive therapies were undertaken on a case-by-case basis. The BVMC HHT cohort targets $25 \%$ brain VM-positive patients; other characteristics are similar to other cohorts $[20,21]$.

Analysis Vital status, organ VMs, genetics and clinical data were collected at baseline. We tested whether organ VMs, HHT symptoms and HHT genes were individually associated with increased mortality using Cox proportional hazards regression analysis, adjusting for patient age (modeled as a categorical variable: 0-19, 20-39, $40-59$, or $60+$ years old), sex, and smoking history (current or past smoker versus never smoker). Additionally, we used a backward elimination procedure, keeping in patient age, sex, and smoking history, to determine which symptoms contributed to a multivariable regression 
model. For this procedure, we sequentially removed predictors with the largest $p$ value until all included predictors had a $p$ value less than 0.05 . Since some clinical data was missing, we re-ran all Cox regression analyses using 10 imputation data sets created using the chained equations imputation technique. Finally, we generated Kaplan-Meier curves stratified by various groupings. Cox regression results are reported as hazard ratios (HR) with $95 \%$ confidence intervals $(\mathrm{CI}) . P$ values less than 0.05 were considered significant. Stata 15.1 was used to perform statistical analyses (StataCorp. 2017. Stata Statistical Software: Release 15. College Station, TX: StataCorp LLC.).

\section{Results}

Patient characteristics are reported in Table 1, including demographics, HHT manifestations, and gene mutations.

59 deaths occurred, of 1286 patients, during mean follow-up time of 3.4 years (maximum follow-up time was 8.6 years with total 4411 patient-years of followup). Cox regression analyses results are summarized in Table 2. GI bleeding was associated with increased mortality $(\mathrm{HR}=2.63,95 \% \mathrm{CI} 1.46-4.74, p=0.001)$, as were symptomatic liver VMs $(\mathrm{HR}=2.10,95 \%$ CI 1.15 $3.84, p=0.015)$. History of anemia was also associated with increased mortality $(\mathrm{HR}=2.93,95 \%$ CI $1.37-6.26$, $p=0.006)$. Note that GI bleeding, liver VMs, and history

Table 1 Demographic data, HHT manifestations, and gene mutations

\begin{tabular}{llll}
\hline Characteristics & Overall & Alive & Dead \\
\hline Count & 1286 & 1227 & 59 \\
$\begin{array}{l}\text { Age at enrollment, } \\
\text { mean } \pm \text { SD }\end{array}$ & $46.0 \pm 19.7$ & $45.3 \pm 19.5$ & $60.8 \pm 18.0$ \\
Age category & & & \\
$\quad<20$ & $171(13 \%)$ & $168(14 \%)$ & $3(5 \%)$ \\
$20-39$ & $263(20 \%)$ & $258(21 \%)$ & $5(8 \%)$ \\
$40-59$ & $511(40 \%)$ & $500(41 \%)$ & $11(19 \%)$ \\
$>60$ & $341(27 \%)$ & $301(25 \%)$ & $40(68 \%)$ \\
Female & $749(58 \%)$ & $718(59 \%)$ & $31(53 \%)$ \\
Smoker (past or cur- & $428 / 1231(35 \%)$ & $395 / 1178(34 \%)$ & $33 / 53(62 \%)$ \\
$\quad$ rent) & & & \\
Brain VM & $278(22 \%)$ & $268(22 \%)$ & $10(17 \%)$ \\
Pulmonary AVM & $615 / 1235(50 \%)$ & $585 / 1178(50 \%)$ & $30 / 57(53 \%)$ \\
Symptomatic liver VM & $217 / 1217(18 \%)$ & $196 / 1162(17 \%)$ & $21 / 55(38 \%)$ \\
Gl bleeding & $216 / 1233(18 \%)$ & $189 / 1177(16 \%)$ & $27 / 56(48 \%)$ \\
Anemia & $591 / 1234(48 \%)$ & $550 / 1181(47 \%)$ & $41 / 53(77 \%)$ \\
Genotype & & & \\
ACVRL1 & $357 / 886(40 \%)$ & $343 / 854(40 \%)$ & $14 / 32(44 \%)$ \\
ENG & $496 / 886(56 \%)$ & $482 / 854(56 \%)$ & $14 / 32(44 \%)$ \\
SMAD4 & $33 / 886(4 \%)$ & $29(3 \%)$ & $4 / 32(13 \%)$ \\
\hline
\end{tabular}

Values are $\mathrm{n}(\%)$ or $\mathrm{n} /$ total $(\%)$, unless otherwise specified
Table 2 Cox regression results of HHT manifestations and gene mutations

\begin{tabular}{lclr}
\hline Characteristic & HR & 95\% Cl & $\boldsymbol{p}$ value \\
\hline Brain VM & 0.76 & $(0.35,1.66)$ & 0.494 \\
Pulmonary AVM & 1.12 & $(0.64,1.96)$ & 0.681 \\
Symptomatic Liver VM & 2.10 & $(1.15,3.84)$ & 0.015 \\
Gl bleeding & 2.63 & $(1.46,4.74)$ & 0.001 \\
Anemia & 2.93 & $(1.37,6.26)$ & 0.006 \\
ACVRL1 (vs. ENG) & 1.54 & $(0.70,3.38)$ & 0.286 \\
SMAD4 (vs. ACVRL1/ENG) & 18.36 & $(5.60,60.20)$ & $<0.001$ \\
\hline
\end{tabular}

Characteristics were tested individually, while adjusting for age, sex, and smoking status

of anemia were associated with one another at baseline (Fisher's exact test $p<0.001$ for all three possible pairings). Brain VMs and pulmonary AVMs were not significantly associated with mortality $(p>0.05)$. Patients with SMAD4 mutation had significantly higher mortality $(\mathrm{HR}=18.36,95 \%$ CI $5.60-60.20, p<0.001)$ compared to patients with $A C V R L 1 / E N G$ mutations, but the estimate is imprecise given the rarity of $S M A D 4$ patients $(\mathrm{n}=33$, 4 deaths). There was no significant difference in mortality between patients with ACVRL1 and ENG mutation $(p>0.05)$. The backward elimination procedure identified a model that included both anemia $(\mathrm{HR}=2.44,95 \%$ CI 1.10-5.42, $p=0.028)$ and GI bleeding ( $\mathrm{HR}=2.25$, 95\% CI 1.21-4.18, $p=0.010$ ). Cox regression analyses of each characteristic individually using imputed data largely agreed with the complete-case analyses and are presented in the Additional file 1: Table S1. Performing the backward elimination procedure on the imputed data retained only GI bleeding as a significant predictor $(\mathrm{HR}=2.77,95 \%$ CI $1.60-4.82, p<0.001)$.

Kaplan-Meier survival curves are displayed in Fig. 1, for age, symptomatic liver VM, anemia, GI bleeding, pulmonary AVM, brain VM and genotype (SMAD4 vs ACVRL1/ENG).

\section{Cause of death}

Detailed chart review for cause of death was available in 46 patients: 23 died from HHT or JP-HHT related complications; 23 died from non-HHT causes. Cause of death was unavailable or unknown in the other 13 patients. In the 23 patients who died from HHT or JPHHT related complications, specific causes included heart failure from liver VMs (6), chronic severe HHTrelated bleeding (7), brain abscess (2, including one with diffuse pulmonary AVM), staph infections (2), pulmonary hemorrhage (1, in a SMAD4 patient with JP-HHT and diffuse pulmonary AVMs), pulmonary hypertension (2), acute rejection post-liver transplant for liver VMs 

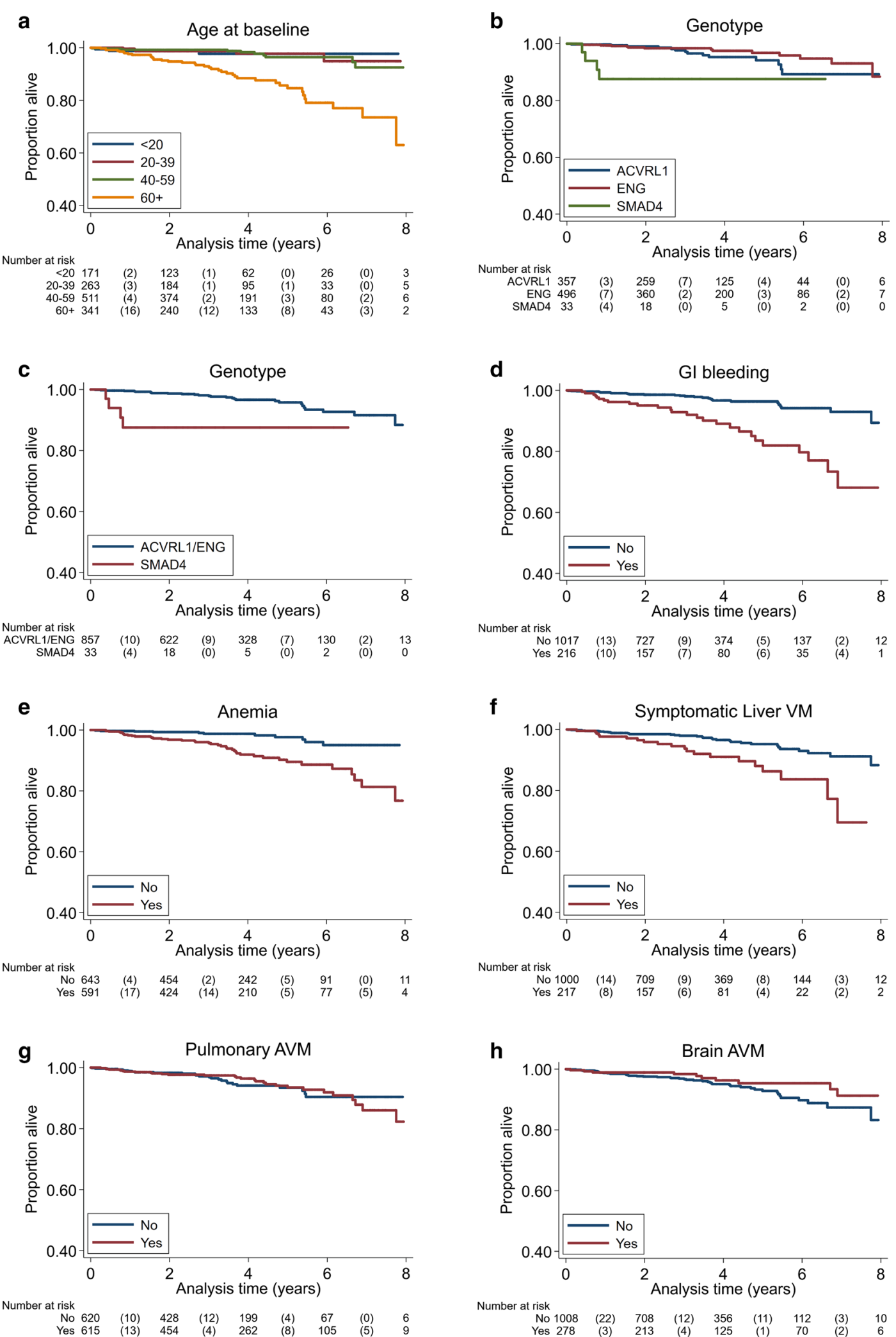

Fig. 1 Kaplan-Meier survival curves for age (a), genotype (b, c), Gl bleeding (d), anemia (e), symptomatic liver VM (f), pulmonary AVM (g), and brain VM (h) 
(1), intracranial hemorrhage (1) and metastatic colon cancer (in a SMAD4 patient with HHT, at the age of 29). Of the 23 deaths from non-HHT causes, specific causes included cancer (7), accident (3), pulmonary fibrosis (2), myocardial infarction (1), congestive heart failure (1), pneumonia (1), COPD (1), dementia (1), stroke (1), hepatitis $C(1)$, venous thromboembolism (1) and "natural causes" (3).

\section{Discussion}

In this large, multi-center prospective study of HHT patients cared for in specialized HHT centers, we demonstrate that HHT-related GI bleeding, anemia and symptomatic liver VMs are predictors of mortality. This is in keeping with the limited treatment options for these aspects of HHT and highlights the importance of development and trials for new therapies for these aspects of HHT.

We demonstrate here that GI bleeding and anemia are predictors of mortality, independent of age, in both the univariate and multivariable models. GI bleeding is also shown to be a predictor of mortality in the imputed data model. This is despite specialized center care according to HHT guidelines, typically including supportive management of anemia and also endoscopic management of clinically evident GI bleeding, with consideration for additional agents such as tranexamic acid or other medical therapies, though this management data was not collected. These results are in keeping with results from an earlier cohort at the Toronto HHT Centre, reporting reduced survival in HHT patients with GI bleeding, in abstract form [22]. Others have demonstrated that GI bleeding is a frequent cause for emergency room visits and hospitalization amongst $\mathrm{HHT}$ patients $[8,18]$ and patients with GI involvement require more blood transfusions, emergency room visits and hospital admissions compared to other HHT patients [23], all supporting the significant morbidity associated with this complication of HHT. In our series, several deaths were the result of chronic severe bleeding. The morbidity and mortality associated with HHT-related GI bleeding suggests an urgent need for the development of new therapies for GI bleeding and anemia. Systemic therapies are of particular interest, given that GI bleeding typically occurs from a large number of small lesions [24], and supported by recent promising reports of intravenous bevacizumab [25] and oral pazopanib [26] for management of severe GI bleeding, as well as chronic epistaxis.

We also demonstrate that the presence of symptomatic liver VMs is a predictor of mortality in the univariate model, though it did not remain a significant predictor in the multivariable model likely due to overlap with GI bleeding, given that both are associated with ACVRL1 mutation [27]. The association between liver VMs and mortality was observed despite specialized center care for liver VMs according to HHT guidelines [6] and its complications, typically including supportive and medical management of high-output heart failure, portal hypertension, and biliary ischemia, and consideration for liver transplantation and intravenous bevacizumab in severe and refractory cases, though this management data was not collected. These results are in keeping with an earlier report of significant morbidity and mortality from liver VMs in HHT patients, with 25\% of liver VM patients experiencing complications and 5\% death from liver VM-related complications [28] over a median 44 months of follow-up. In our series, liver VMs were the most common cause of death. Given the demonstrated morbidity and mortality associated with liver VMs, once again there is an urgent need for new therapies. Successful liver transplantation for liver VMs has been reported [29], as has management with intravenous bevacizumab $[30,31]$, though these are limited and expensive options, considered only presently for those with severe and symptomatic liver VMs. Again, novel systemic therapies would potentially have the particular advantage of simultaneously addressing the riskiest aspects of HHT: liver VMs and chronic GI bleeding.

Brain VMs and pulmonary AVMs are not predictors of mortality in center-based care HHT patients reported here. We speculate that this result is due to current routine screening and preventative treatment of pulmonary AVMs in specialized HHT Centres, as well as screening and preventative treatment of brain VMs in selected HHT patients. Although 3 of the documented deaths in our study were related to pulmonary AVM complications, 2 of these 3 deaths occurred in patients with diffuse pulmonary AVMs. Patients with diffuse pulmonary AVMs are a rare severe subset (5\%) of the patients with pulmonary AVMs, with significant morbidity, including high risk of neurologic complications, and mortality $[32,33]$. In other words, though diffuse pulmonary AVMs were an important cause of death in our series, overall the presence of pulmonary AVMs was not associated with mortality. This underlines the importance of developing therapies for patients with the rare form of diffuse pulmonary AVMs; it also supports the current practice of preventative screening and management of the typical pulmonary AVMs, as per HHT Guidelines [6], and the recent recommendation by the European Reference Network for Rare Vascular Diseases (VASCERN) proposing pulmonary AVM screening as one of five metrics to identify healthcare providers of good care [34].

We observed that SMAD4 mutation is associated with higher mortality compared to ACVRL1 or ENG mutation in the univariate and imputed data models. However, this 
estimate is imprecise given the small number of SMAD4 patients. HHT patients with SMAD4 mutation typically have an overlap syndrome with Juvenile Polyposis (JP), with patients developing both JP and HHT phenotypes $[35,36]$, with risk of early-onset gastrointestinal cancer and associated mortality $[37,38]$ In other words, the JP-associated risk of colorectal cancer in patients with SMAD4 mutation may explain the observed mortality association with $S M A D 4$ in this study.

The findings of this study should be considered in light of some potential limitations. First, there were some missing data regarding organ involvement and detailed cause of death. However secondary survival analyses using imputed data supported the association of GI bleeding with mortality. Second, information regarding severity of epistaxis was not available and so epistaxis severity could not be studied as a predictor of HHT mortality or in relation to anemia. Similarly, information on the severity of liver VMs, brain VMs, and pulmonary AVMs, as well as the lesional burden of GI telangiectasia, was not available for this study, rather the analyses were performed based on their presence or absence. This may have led us to underestimate the association between organ VMs and mortality. In other words, this may have limited our power to detect a mortality association for brain VMs, for example. However, despite this limitation, we detected significant associations for liver VMs, GI bleeding and anemia, supporting the significance of these results. Information on mediations that might influence mortality and bleeding, such as anti-platelet and anticoagulant medications was not available and therefore not adjusted for in the analyses. Another potential limitation of this study is survivor bias, particularly relevant to brain VMs, given brain VMs can cause mortality in children with HHT [39], and this may have prevented us from detecting an association with mortality. Finally, we did not collect detailed data on clinical management of patient's organ VMs, though all participating centers report following standard practice according to the 2009 International HHT Guidelines.

\section{Conclusions}

Chronic GI bleeding, anemia, and symptomatic liver VMs are associated with increased mortality in HHT patients, independent of age, and in keeping with the limited treatment options available for these aspects of HHT. Conversely, mortality does not appear to be associated with pulmonary AVMs or brain VMs, for which patients are routinely screened and treated preventatively at HHT Centers. This demonstrates the urgent need for development of new therapies to preventatively treat chronic GI bleeding, anemia, and symptomatic liver VMs in order to reduce mortality among HHT patients.

\section{Supplementary information}

Supplementary information accompanies this paper at https://doi. org/10.1186/s13023-020-01579-2.

Additional file 1: Table S1. Imputed Cox regression results of HHT manifestations and gene mutations.

\section{Acknowledgements}

Brain Vascular Malformation Consortium HHT Investigator Group: Murali Chakinala, Marianne S. Clancy, Marie E. Faughnan, James R. Gossage, Katharine Henderson, Vivek lyer, Raj S. Kasthuri, Helen Kim, Timo Krings, Michael T. Lawton, Doris Lin, Hans-Jurgen Mager, Douglas A. Marchuk, Justin P. McWilliams, Jamie McDonald, Ludmila Pawlikowska, Jeffrey Pollak, Felix Ratjen, Karen Swanson, Karel terBrugge, Dilini Vethanayagam, Andrew J. White, Pearce Wilcox.

\section{Authors' contributions}

All authors contributed to the study and to the manuscript. KPT and MEF drafted the manuscript. JN, HK and LP provided analytic expertise and participated with manuscript preparation. DAM and MTL provided content expertise. All other authors recruited patients, collected data and provided input on the manuscript. All authors read and approved the final manuscript.

\section{Funding}

The Brain Vascular Malformation Consortium (U54NS065705) is a part of the NCATS Rare Diseases Clinical Research Network (RDCRN) and is supported by the RDCRN Data Management and Coordinating Center (DMCC) (U2CTR002818). RDCRN is an initiative of the Office of Rare Diseases Research (ORDR), NCATS, funded through a collaboration between NCATS and NINDS. M.E.F. was also supported by the Nelson Arthur Hyland Foundation and Li Ka Shing Knowledge Institute.

\section{Availability of data and materials}

All data generated or analyzed during this study are included in this published article and its supplementary information files.

\section{Ethics approval and consent to participate}

All participating centers had ethics approval from their institutional review board and all participants provided informed consent.

\section{Consent for publication}

Not applicable.

\section{Competing interests}

The authors declare that they have no competing interests.

\section{Author details}

${ }^{1}$ Toronto HHT Centre, Li Ka Shing Knowledge Institute, St. Michael's Hospital, 30 Bond St, Toronto, ON M5B-1W8, USA. ${ }^{2}$ Division of Respirology, Department of Medicine, University of Toronto, Toronto, Canada. ${ }^{3}$ Department of Anesthesia and Perioperative Care, Center for Cerebrovascular Research, University of California, San Francisco, CA, USA. ${ }^{4}$ Institute for Human Genetics, University of California, San Francisco, CA, USA. ${ }^{5}$ Department of Epidemiology and Biostatistics, University of California, San Francisco, CA, USA. ${ }^{6}$ Department of Molecular Genetics and Microbiology, Duke University Medical Center, Durham, NC, USA. ${ }^{7}$ Barrow Neurological Institute, Phoenix, AZ, USA.

Received: 11 July 2020 Accepted: 13 October 2020

Published online: 06 January 2021

\section{References}

1. Dakeishi M, Shioya T, Wada Y, Shindo T, Otaka K, Manabe M, Nozaki J, Inoue S, Koizumi A. Genetic epidemiology of hereditary hemorrhagic telangiectasia in a local community in the northern part of Japan. Hum Mutat. 2002;19(2):140-8. 
2. Grosse SD, Boulet SL, Grant AM, Hulihan MM, Faughnan ME. The use of US health insurance data for surveillance of rare disorders: hereditary hemorrhagic telangiectasia. Genet Med. 2014;16(1):33-9.

3. Donaldson JW, McKeever TM, Hall IP, Hubbard RB, Fogarty AW. The UK prevalence of hereditary haemorrhagic telangiectasia and its association with sex, socioeconomic status and region of residence: a populationbased study. Thorax. 2014;69(2):161-7.

4. Bideau A, Plauchu H, Brunet G, Robert J. Epidemiological investigation of Rendu-Osler disease in France: its geographical distribution and prevalence. Population. 1989;44(1):3-22.y

5. Chowdhury FN, Chandrarathne GS, Masilamani KD, LaBranche JTN, Malo S, Svenson LW, Jeerakathil T, Vethanayagam DP. Links between strokes and hereditary hemorrhagic telangiectasia: a population-based study. Can J Neurol Sci. 2019;46(1):44-50.

6. Faughnan ME, Palda VA, Garcia-Tsao G, Geisthoff UW, McDonald J, Proctor DD, Spears J, Brown DH, Buscarini E, Chesnutt MS, Cottin V, Ganguly A, Gossage JR, Guttmacher AE, Hyland RH, Kennedy SJ, Korzenik J, Mager JJ, Ozanne AP, Piccirillo JF, Picus D, Plauchu H, Porteous ME, Pyeritz RE, Ross DA, Sabba C, Swanson K, Terry P, Wallace MC, Westermann CJ, White RI, Young LH, Zarrabeitia R, Group HHTFI-GW. International guidelines for the diagnosis and management of hereditary haemorrhagic telangiectasia. J Med Genet 2011;48(2):73-87.

7. Guttmacher AE, Marchuk DA, White RI Jr. Hereditary hemorrhagic telangiectasia. N Engl J Med. 1995:333(14):918-24.

8. Gallitelli M, Pasculli G, Fiore T, Carella A, Sabba C. Emergencies in hereditary haemorrhagic telangiectasia. QJM. 2006;99(1):15-22.

9. Shovlin $\mathrm{CL}$, Jackson JE, Bamford KB, Jenkins IH, Benjamin AR, Ramadan $\mathrm{H}$, Kulinskaya E. Primary determinants of ischaemic stroke/brain abscess risks are independent of severity of pulmonary arteriovenous malformations in hereditary haemorrhagic telangiectasia. Thorax. 2008:63(3):259-66.

10. Garcia-Tsao G, Korzenik JR, Young L, Henderson KJ, Jain D, Byrd B, Pollak JS, White RI Jr. Liver disease in patients with hereditary hemorrhagic telangiectasia. N Engl J Med. 2000;343(13):931-6.

11. Donaldson JW, McKeever TM, Hall IP, Hubbard RB, Fogarty AW. Complications and mortality in hereditary hemorrhagic telangiectasia: a population-based study. Neurology. 2015;84(18):1886-93.

12. Akers AL, Ball KL, Clancy M, Comi AM, Faughnan ME, Gopal-Srivastava R, Jacobs TP, Kim H, Krischer J, Marchuk DA, McCulloch CE, Morrison L, Moses M, Moy CS, Pawlikowska L, Young WL. Brain vascular malformation consortium: overview, progress and future directions. J Rare Disord. 2013;1(1):5.

13. Sabba C, Pasculli G, Suppressa P, D'Ovidio F, Lenato GM, Resta F, Assennato G, Guanti G. Life expectancy in patients with hereditary haemorrhagic telangiectasia. QJM. 2006;99(5):327-34.

14. de Gussem EM, Edwards CP, Hosman AE, Westermann CJ, Snijder RJ, Faughnan ME, Mager JJ. Life expectancy of parents with Hereditary Haemorrhagic Telangiectasia. Orphanet J Rare Dis. 2016;11:46.

15. Droege F, Thangavelu K, Stuck BA, Stang A, Lang S, Geisthoff U. Life expectancy and comorbidities in patients with hereditary hemorrhagic telangiectasia. Vasc Med. 2018;23(4):377-83.

16. Kjeldsen A, Aagaard KS, Torring PM, Moller S, Green A. 20-year follow-up study of Danish HHT patients-survival and causes of death. Orphanet J Rare Dis. 2016;11:157.

17. Iyer VN, Brinjikji W, Pannu BS, Apala DR, Lanzino G, Cloft HJ, Misra S, Krowka MJ, Wood CP, Swanson KL. Effect of center volume on outcomes in hospitalized patients with hereditary hemorrhagic telangiectasia. Mayo Clin Proc. 2016:91(12):1753-60.

18. Brinjikji W, Wood CP, Lanzino G, Cloft HJ, Misra S, Kallmes DF, Kamath P, Pruthi RK, Krowka MJ, Swanson KL, Iyer VN. High rates of bleeding complications among hospitalized patients with hereditary hemorrhagic telangiectasia in the United States. Ann Am Thorac Soc. 2016;13(9):1505-11.

19. Pawlikowska L, Nelson J, Guo DE, McCulloch CE, Lawton MT, Young WL, Kim H, Faughnan ME. The ACVRL1 c.314-35A>G polymorphism is associated with organ vascular malformations in hereditary hemorrhagic telangiectasia patients with ENG mutations, but not in patients with ACVRL1 mutations. Am J Med Genet A 2015;167(6):1262-7.

20. Letteboer TG, Mager JJ, Snijder RJ, Koeleman BP, Lindhout D, Ploos van Amstel JK, Westermann CJ. Genotype-phenotype relationship in hereditary haemorrhagic telangiectasia. J Med Genet 2006;43(4):371-7.
21. Nishida T, Faughnan ME, Krings T, Chakinala M, Gossage JR, Young WL, Kim H, Pourmohamad T, Henderson KJ, Schrum SD, James M, Quinnine N, Bharatha A, terBrugge KG, White RI Jr. Brain arteriovenous malformations associated with hereditary hemorrhagic telangiectasia: genotype-phenotype correlations. Am J Med Genet A. 2012;158A(11):2829-34.

22. Goodwin J, Nisenbaum R, Edwards CP, Faughnan ME. Pulmonary arteriovenous malformations and survival. Am J Respir Crit Care Med. 2010;181:A4817.

23. Mora-Luján JM, Iriarte A, Alba E, Sánchez-Corral MÁ, Berrozpe A, Cerdà P, Cruellas F, Ribas J, Castellote J, Riera-Mestre A. Gastrointestinal bleeding in patients with hereditary hemorrhagic telangiectasia: risk factors and endoscopic findings. J Clin Med. 2019;9(1):82.

24. Jackson SB, Villano NP, Benhammou JN, Lewis M, Pisegna JR, Padua D. Gastrointestinal manifestations of hereditary hemorrhagic telangiectasia (HHT): A systematic review of the literature. Dig Dis Sci. 2017:62(10):2623-30.

25. Iyer VN, Apala DR, Pannu BS, Kotecha A, Brinjikji W, Leise MD, Kamath PS, Misra S, Begna KH, Cartin-Ceba R, DuBrock HM, Krowka MJ, O'Brien EK, Pruthi RK, Schroeder DR, Swanson KL. Intravenous bevacizumab for refractory hereditary hemorrhagic telangiectasia-related epistaxis and gastrointestinal bleeding. Mayo Clin Proc. 2018;93(2):155-66.

26. Faughnan ME, Gossage JR, Chakinala MM, Oh SP, Kasthuri R, Hughes CCW, McWilliams JP, Parambil JG, Vozoris N, Donaldson J, Paul G, Berry P, Sprecher DL. Pazopanib may reduce bleeding in hereditary hemorrhagic telangiectasia. Angiogenesis. 2019;22(1):145-55.

27. Canzonieri C, Centenara L, Ornati F, Pagella F, Matti E, Alvisi C, Danesino C, Perego M, Olivieri C. Endoscopic evaluation of gastrointestinal tract in patients with hereditary hemorrhagic telangiectasia and correlation with their genotypes. Genet Med. 2014;16(1):3-10.

28. Buscarini E, Leandro G, Conte D, Danesino C, Daina E, Manfredi G, Lupinacci G, Brambilla G, Menozzi F, De Grazia F, Gazzaniga P, Inama G, Bonardi R, Blotta P, Forner P, Olivieri C, Perna A, Grosso M, Pongiglione G, Boccardi E, Pagella F, Rossi G, Zambelli A. Natural history and outcome of hepatic vascular malformations in a large cohort of patients with hereditary hemorrhagic teleangiectasia. Dig Dis Sci. 2011;56(7):2166-78.

29. Lerut J, Orlando G, Adam R, Sabba C, Pfitzmann R, Klempnauer J, Belghiti J, Pirenne J, Thevenot T, Hillert C, Brown CM, Gonze D, Karam V, Boillot O, European Liver Transplant A. Liver transplantation for hereditary hemorrhagic telangiectasia: report of the European liver transplant registry. Ann Surg 2006;244(6):854-62.

30. Dupuis-Girod S, Ginon I, Saurin JC, Marion D, Guillot E, Decullier E, Roux A, Carette MF, Gilbert-Dussardier B, Hatron PY, Lacombe P, Lorcerie B, Riviere S, Corre R, Giraud S, Bailly S, Paintaud G, Ternant D, Valette PJ, Plauchu H, Faure F. Bevacizumab in patients with hereditary hemorrhagic telangiectasia and severe hepatic vascular malformations and high cardiac output. JAMA. 2012;307(9):948-55.

31. Al-Samkari H, Albitar HA, Olitsky SE, Clancy MS, Iyer VN. Systemic bevacizumab for high-output cardiac failure in hereditary hemorrhagic telangiectasia: an international survey of HHT centers. Orphanet J Rare Dis. 2019;14(1):256.

32. Faughnan ME, Lui YW, Wirth JA, Pugash RA, Redelmeier DA, Hyland RH, White RI Jr. Diffuse pulmonary arteriovenous malformations: characteristics and prognosis. Chest. 2000;117(1):31-8.

33. Pierucci P, Murphy J, Henderson KJ, Chyun DA, White RI Jr. New definition and natural history of patients with diffuse pulmonary arteriovenous malformations: twenty-seven-year experience. Chest. 2008;133(3):653-61.

34. Shovlin CL, Buscarini E, Kjeldsen AD, Mager HJ, Sabba C, Droege F, Geisthoff U, Ugolini S, Dupuis-Girod S. European reference network for rare vascular diseases (VASCERN) outcome measures for hereditary Haemorrhagic telangiectasia (HHT). Orphanet J Rare Dis. 2018;13(1):1-5.

35. Gallione CJ, Repetto GM, Legius E, Rustgi AK, Schelley SL, Tejpar S, Mitchell G, Drouin E, Westermann CJ, Marchuk DA. A combined syndrome of juvenile polyposis and hereditary haemorrhagic telangiectasia associated with mutations in MADH4 (SMAD4). Lancet. 2004;363(9412):852-9.

36. Gallione CJ, Richards JA, Letteboer TG, Rushlow D, Prigoda NL, Leedom TP, Ganguly A, Castells A, Ploos van Amstel JK, Westermann CJ, Pyeritz RE, Marchuk DA. SMAD4 Mutations found in unselected HHT patients. J Med Genet 2006;43(10):793-7.

37. Tam B, Salamon A, Bajtai A, Nemeth A, Kiss J, Simon L, Molnar T. The real face of juvenile polyposis syndrome. J Gastrointest Oncol. 2012:3(4):362-8. 
38. Schwenter F, Faughnan ME, Gradinger AB, Berk T, Gryfe R, Pollett A, Cohen Z, Gallinger S, Durno C. Juvenile polyposis, hereditary hemorrhagic telangiectasia, and early onset colorectal cancer in patients with SMAD4 mutation. J Gastroenterol. 2012;47(7):795-804.

39. Morgan T, McDonald J, Anderson C, Ismail M, Miller F, Mao R, Madan A, Barnes $P$, Hudgins $L$, Manning $M$. Intracranial hemorrhage in infants and children with hereditary hemorrhagic telangiectasia (Osler-Weber-Rendu syndrome). Pediatrics. 2002;109(1):E12.

\section{Publisher's Note}

Springer Nature remains neutral with regard to jurisdictional claims in published maps and institutional affiliations.
Ready to submit your research? Choose BMC and benefit from:

- fast, convenient online submission

- thorough peer review by experienced researchers in your field

- rapid publication on acceptance

- support for research data, including large and complex data types

- gold Open Access which fosters wider collaboration and increased citations

- maximum visibility for your research: over $100 \mathrm{M}$ website views per year

At BMC, research is always in progress.

Learn more biomedcentral.com/submissions 